\title{
Over-the-counter whitening agents: a concise review $\$$
}

\section{Flávio Fernando Demarco(a) Sônia Saeger Meireles(b) Alexandre Severo Masotti ${ }^{(c)}$}

\footnotetext{
(a) PhD, Associate Professor, Department of Operative Dentistry, School of Dentistry, Federal University of Pelotas, Pelotas, RS, Brazil.

(b) PhD, Adjunct Professor, Department of Operative Dentistry, School of Dentistry, Federal University of Paraíba, João Pessoa, PB, Brazil.

(c) PhD, Adjunct Professor, Department of Semiology and Clinic, School of Dentistry, Federal University of Pelotas, Pelotas, RS, Brazil.
}

\$Paper presented at the "Oral Health Self-Care Products: Realities and Myths" international symposium, sponsored by the Brazilian Association for Oral Health Promotion (ABOPREV), September 25-27, 2008, São Paulo, SP, Brazil.

\section{Corresponding author:}

Flávio Fernando Demarco

Faculdade de Odontologia - Programa de Pós Graduação em Odontologia

Rua Gonçalves Chaves, 457 - Centro

Pelotas - RS - Brazil

CEP: 96015-560

E mail:ffdemarco@hotmail.com

Received for publication on Nov 18, 2008

Accepted for publication on Dec 05, 2008

\begin{abstract}
Tooth discoloration is commonly found in the dental clinic and tooth bleaching has been considered the preferred esthetic alternative, being more conservative, safe and with predictable results. Supervised home-use of $10 \%$ Carbamide Peroxide (CP) bleaching with custom-trays is the most common bleaching procedure dispensed by dentists to their patients. The good results obtained with this technique stimulated the flourishing of new products and techniques. Over-the-counter (OTC) bleaching products appeared as a low-cost alternative to bleach discolored teeth without dentist supervision. Different OTC products are available in supermarkets, drug stores or on the Internet, including rinses, paint-on brushes, toothpastes, chewing guns, dental floss, and whitening strips. There is lack of clinical evidence regarding the safety and effectiveness of these products, being most of the studies supported by the manufacturers'. Basically, toothpastes, chewing gums, and dental floss are removal agents of superficial stains. Rinses and paint-on brushes with low levels of hydrogen peroxide have some whitening effect, but without clinical relevance. Strips present similar esthetic results and side-effects, compared to bleaching with $10 \% \mathrm{CP}$ using trays; however, the studies have financial support from the manufacturers and were based on short term evaluations. Legislation varies widely in different countries regarding OTC dental bleaching. Concerns have appeared due to the potential abusive use of these self-medication agents, especially in young patients, with potential harmful results. Dentists should be acquainted with this kind of products to be able to inform their patients. In conclusion, there is a need for independent clinical trials to provide sufficient evidence regarding the use of OTC bleaching products.
\end{abstract}

Descriptors: Tooth bleaching; Over-the-counter drugs; Peroxides; Review. 


\section{Introduction}

Esthetic dentistry has received increased attention in recent years, especially due to the fact that people are more concerned about the esthetic appearance of their smile. This fact, associated with the decrease in the incidence and severity of caries, has directed the clinician's attention to conservative and non-invasive treatments, like tooth bleaching.

Tooth discoloration can be influenced by a combination of intrinsic and extrinsic factors. Intrinsic stains are related to enamel and dentin properties, while extrinsic stains are associated to deposition of either food or beverages stains on the tooth surface. ${ }^{1}$ A number of methods are available to improve the color of teeth such as whitening toothpastes, professional stain removal, enamel microabrasion, vital tooth bleaching, non-vital tooth bleaching, crowns and veneers. ${ }^{2}$

Dentist-supervised home-use tooth bleaching with custom trays is the most common bleaching procedure dispensed by dentists to their patients. ${ }^{3}$ Usually, this treatment modality consists in the application of $10 \%$ carbamide peroxide in a tray that is worn at night for at least two weeks. This concentration is more accepted than others, due to excellent esthetic results and low incidence of side effects. ${ }^{3-5}$ The most common adverse effects reported for at-home bleaching systems are tooth sensitivity and gingival irritation, which disappear when the bleaching treatment is stopped or an agent like potassium nitrate or sodium fluoride is applied. ${ }^{3}$ Until now, only the $10 \pm 1 \%$ carbamide peroxide concentration received the seal of acceptance by the American Dental Association (ADA), which assures its safety and efficacy for at-home tooth bleaching. ${ }^{6}$

The benefits achieved with bleaching systems with trays associated with the consumers' and patients' needs have stimulated the marketing of overthe-counter (OTC) products for at-home tooth bleaching. OTC products appeared in the USA in the beginning of the 2000s, as an alternative to treat tooth discoloration with lower cost than traditional professional-prescribed/guided products. ${ }^{7}$ The proliferation of these OTC products in the USA was in a certain way stimulated by the Food and Drug Administration (FDA). According to the FDA, these products could reduce inequity in the access to the health system, reducing the cost of treatments. ${ }^{8}$

Currently, gels, rinses, gums, dentifrices, whitening strips or paint-on films ${ }^{3,6,9}$ with low levels of carbamide or hydrogen peroxide are widely available to consumers at pharmacies, supermarkets and over the Internet. ${ }^{2}$ However, these self-applied bleaching treatments can be harmful and the results may not be as good as those offered by dentist-guided treatments. Additionally, there is a lack of clinical trials that provide substantial scientific background regarding these whitening products. Thus, this review evaluates and discusses the current knowledge concerning efficacy, mechanism of action, and legislation of the OTC tooth-bleaching products.

\section{Critical assessment of the OTC products for home-use bleaching}

In this session, the data related to composition, mechanism of action, efficacy and side effects of OTC products available for home-use bleaching are discussed.

\section{Whitening dentifrices}

Toothpastes that claim to have tooth-whitening properties represent more than $50 \%$ of the OTC products and rarely contain carbamide or hydrogen peroxide, or any other kind of bleaching agent. ${ }^{9}$ Their stain-removal ability is related to the large quantity of abrasives in their formulation, which remove superficial extrinsic stains. ${ }^{10}$ The active components of tooth whitening dentifrices include enzymes that break down the organic molecules of biological film. Additionally, abrasives such as alumina, dicalcium phosphate dihydrate and silica are also present in the formulation to promote stain-removal. ${ }^{1}$ However, the toothpaste abrasiveness needs to be moderated in order to prevent excessive wear to the underlying enamel and dentine. ${ }^{11}$

A number of studies have been published to measure changes in tooth color after regular whitening toothpaste use. ${ }^{10-12}$ Generally, when whitening dentifrices are compared to non-whitening toothpastes the results have demonstrated that their use can remove and/or prevent extrinsic tooth stains. ${ }^{1,10,13,14}$

Although whitening toothpastes can prevent ex- 
trinsic tooth stains, the whitening effect obtained seems not to be clinically significant. A study that compared the efficacy and safety of three OTC bleaching products $(1 \%$ hydrogen peroxide dentifrice, $18 \%$ carbamide peroxide paint-on gel, and $5 \%$ carbamide peroxide tray system) showed that the group treated with the tray system experienced the greatest color improvement. After 14 days of use, the paint-on gel and dentifrice groups did not result in significant color improvements from baseline. Moreover, tooth sensitivity and oral irritation were the most common safety findings in the tray and dentifrice groups. ${ }^{12}$ Another study evaluated the efficacy and safety of a paint-on gel $(18 \%$ carbamide peroxide), a whitening strip (6\% hydrogen peroxide), and a whitening dentifrice. The authors also observed that there were no significant differences in color improvement for the group treated with the whitening toothpaste compared to baseline. ${ }^{15}$

\section{Rinses}

Whitening mouthrinses appeared recently in the market and manufacturers advertised that they could prevent stains and fight plaque build-up. Generally, a low concentration of hydrogen peroxide $(1.5 \%)$ is present and sodium hexametaphosphate can also be included in the formulation to protect the teeth surface from new stains. A study evaluated the efficacy and safety of a whitening mouthrinse ( $2 \%$ hydrogen peroxide) and whitening strips $(10 \%$ hydrogen peroxide) that were used twice daily during 1 week. The results showed that although both products had been well tolerated, the group treated with the whitening strips experienced a significantly greater tooth color improvement than the whitening mouthrinse group. ${ }^{16}$ It is necessary, however, to be careful with self-applied whitening products that contain peroxide since they have the potential to produce oral irritation and tooth hypersensitivity. ${ }^{6}$

\section{Whitening dental floss and toothbrushes}

Recently, manufacturers of oral care products have developed other methods with alleged whitening properties. Whitening dental floss has been introduced to promote stain reduction around the interproximal and sub-gingival areas. The stain-re- moval properties are associated with the presence of silica in the composition, which promotes a superficial surface abrasion during application in the interdental region. However, no clinical report is available comparing its effectiveness in relation to non-whitening dental floss.

Besides being used in a home oral hygiene routine, manual or power toothbrushes can also be used to maintain the whitening effect or prevent extrinsic stains after bleaching treatments. A clinical study compared the ability of two toothbrushes (power or manual) to maintain the color of whitened teeth after an at-home bleaching treatment with $15 \%$ carbamide peroxide. After 6 months, the post-bleaching results demonstrated that the power toothbrush group showed a better ability to maintain the whitening effect than that of the manual toothbrush group. ${ }^{17}$

\section{Chewing gum}

Chewing gum with sodium hexametaphosphate (4.0 - 7.5\%) has been introduced as an OTC product for home-use bleaching claiming to prevent extrinsic tooth stain formation. A study showed that a chewing gum containing hexametaphosphate reduced stain formation compared to a non-gum treatment. ${ }^{18}$ However, when comparing the stain removal ability of two medicated chewing gums containing nicotine with a whitening chewing gum, it could be observed that the former were more effective in the removal of extrinsic tooth stains than the whitening chewing gum. ${ }^{19}$

\section{Paint-on gels}

Paint-on gels or varnishes are OTC barrier-free whitening products that present hydrogen or carbamide peroxide in a suspension that is brushed by an applicator over the tooth surface and which adheres to enamel. ${ }^{20}$

A study compared the effectiveness of a painton gel $(18 \% \mathrm{CP})$, a whitening strip (6\% hydrogen peroxide) and a placebo (fluoride toothpaste). The strip system was found to produce significantly greater lightening than the paint-on gel or placebo, and there was no significant difference between the paint-on and placebo groups. ${ }^{21}$ The low whitening 
effect presented by paint-on gels could probably be related to the reduced contact time of the whitening agent with the enamel surface.

Another study compared in vitro the effectiveness of four paint-on gels (10\% CP, $19 \%$ sodium percarbonate, urea peroxide, and $8.7 \%$ hydrogen peroxide) dispensed for home-use bleaching with a control group (artificial saliva). The Vita Shade Guide results demonstrated that the groups treated with hydrogen peroxide (5.50 \pm 2.15 units) or sodium percarbonate $(5.60 \pm 1.84$ units) presented the greatest color change, while the CP (3.8 \pm 1.8 units) and urea $(4.37 \pm 1.89$ units) groups did not lighten the color of teeth significantly after two weeks of bleaching regimen. ${ }^{20}$ The results of this study, however, may be an overestimation of the efficacy of these products since the teeth were wrapped in gauze impregnated with an artificial saliva solution. In an oral environment, dilution and rubbing effects over the paint-on whitening agent would occur to a greater extent.

\section{OTC tray with gel activated by light}

A new product has become available recently in drug stores or on the Internet, consisting of a universal tray that can be adapted by the individual himself. This tray then receives a gel that is activated by a compact LED unit. The manufacturer claims that the bleaching effect is similar to that of a supervised at-home bleaching with a tray, but it does not clarify what is the active ingredient. It should be emphasized that light activation does not seem to be necessary to increase or accelerate the bleaching process. ${ }^{22}$ Furthermore, a tray with adaptation problems may cause soft oral tissue damage, occlusal problems and/or poor adhesion to the treatment. ${ }^{6}$

\section{Whitening strips}

These products were created aiming to avoid the use of trays. Adhesive strips containing bleaching agents are bonded to the anterior teeth, and they release the active ingredient during relatively short time periods (5 to 60 minutes), once or twice a day. The active ingredient is hydrogen peroxide (HP) in low concentrations (5 to $14 \%$ ). ${ }^{7}$ Studies have demonstrated that there is an increase in the whitening effect when the strips are used for 28 days compared to 14 days, and that the whitening effect could be maintained for 2 years. ${ }^{23}$

In a recent systematic review, when whitening strips were compared to the ADA recommended bleaching protocol, i.e. $10 \% \mathrm{CP}$ in a tray, a similar bleaching effectiveness was observed. However, tooth sensitivity was more pronounced than that observed when the trays were used. It was also observed that strips with higher concentrations $(14 \%)$ of HP increased both the whitening effect and the side effects when compared to strips containing $6 \%$ of HP. ${ }^{3}$ It should be kept in mind that the $10 \%$ carbamide peroxide gel contains a $3.3 \% \mathrm{HP}$ proportion, almost half of the $6 \%$ concentration found in the strips, but a greater volume of gel is placed in the tray as compared to the amount of active ingredient present in the strips. ${ }^{23}$

Due to the easy method of application, relatively low cost and good esthetic results, the use of strips has become an increasingly popular treatment in the USA. ${ }^{23}$ For example, while dental centers were popularizing expensive bleaching techniques, with the price of a professionally brightened smile in the 400 dollars range, consumers also had the choice of whitening toothpastes that cost from 2 dollars to 8 dollars, but with a low whitening effect, and Procter \& Gamble successfully targeted a new mass market with its 35-dollars Whitestrips. ${ }^{24}$

Considering the pertinent literature, is there enough scientific evidence in relation to the effectiveness of OTC bleaching products? The systematic review performed by Hasson et al. ${ }^{3}$ (2006), showed that from the 416 clinical trials identified, only 25 could fit in the inclusion criteria and most of the included studies presented bias as a result of shortterm evaluations and financial support from the manufacturers. The authors concluded the review emphasizing the need for independent, long-term clinical trials to offer evidence about the effectiveness and safety of the OTC products.

It is important to highlight that a value of 4.0 unit gains using a shade guide has been considered to be clinically significant ${ }^{5}$, and the majority of the OTC bleaching products, but the strips, will produce color improvements lower than this value. 


\section{Organizations' safety guidelines of OTC products for home-use bleaching}

The legislation permitting the commercialization of OTC bleaching products in the USA created a US\$ 38 million market in 2001, which increased 10 times until 2005 (US\$ 351 millions). At the same time, products for in-office bleaching or at-home supervised bleaching originated US\$ 2 billions in sales in 2005, having increased four times when compared to 2000. These values are good enough to stimulate companies to invest more in this growing market. Pharmaceutical companies usually invest twice in marketing compared to the resources invested in research, which bring about a potentially risky situation: abusive usage of drugs by insufficiently informed consumers. ${ }^{25}$ This situation is more complicated in countries like Brazil, where self-medication is a common practice. Economic, political and cultural factors can contribute to the growth and spreading of self-medication, including great availability, irresponsible publicity, pressure to convert prescription-only drugs in over-the-counter products, quality of health care and difficult access to health services, especially in poor countries. ${ }^{26}$ Despite some recommendations indicating bleaching treatments for patients aged 15 years and above, ${ }^{9}$ studies have been performed in patients with ages as early as 9 years. ${ }^{23}$ Young patients (children and teenagers) are strongly susceptible to the irrational use of medications ${ }^{26}$ and this should be kept in mind when indicating OTC bleaching products.

European legislation (Scientific Committee on Cosmetic Products and Non-Food Products Intended for Consumers) regarding the use of HP products has highlighted that products containing 0.1 to $6 \% \mathrm{HP}$ are safe only when administered under professional supervision, and more long-term clinical evaluations should be conducted to evaluate these products. ${ }^{6,27}$

As to the US government position, the FDA classifies HP products as OTC products, based on the current scientific literature showing no contraindication for this kind of products, without the need of professional supervision. However, the FDA points out the risk for potential abusive use of these OTC bleaching products, which are used by one in each four American teenagers. ${ }^{8,28}$ More cautious, the ADA (American Dental Association) has reported the OTC products to be beneficial to the public, but when used under dentist supervision. ${ }^{5}$

The ADF (Association Dentaire Française), in a comprehensive literature review concerning bleaching procedures, emphasized that OTC products should be classified as medical devices, instead of cosmetics, especially due to the crescent overuse. The ADF committee concluded that when bleaching agents are repetitively used without supervision and without real motivations, this must be considered a public health problem. In addition, it has recommended that bleaching agents be used in a reservoir to avoid deglutition, thus preventing potential hazardous problems. ${ }^{9}$ Safety concerns emerge in relation to the abusive use of OTC products, taking into account that nowadays younger patients are looking for bleaching procedures. ${ }^{7,23}$

In relation to carcinogenesis, high hydrogen peroxide concentrations may act as a promoter of oral lesions together with other known carcinogenic products (tobacco, alcohol), but low concentrations of carbamide peroxide are considered to be safe, and some recommendations should be directed to patients and clinicians, such as to protect the oral soft tissues when applying high HP concentration agents (in office bleaching), to use low concentration agents and for short periods of time. ${ }^{6}$ Care should also be taken to avoid deglutition of peroxide agents.

Regarding the Brazilian regulations, all bleaching products are considered to be cosmetics (Degree II), being subject to regulations similar to those of toothpastes containing fluoride. Thus, an individual can easily buy bleaching agents, without any restriction, as long as they are registered in the $\mathrm{Na}$ tional Sanitary Survey Agency (Agência Nacional de Vigilância Sanitária - ANVISA). Moreover, the advertisement regulations are more lax when OTC products are considered as cosmetics instead of medical devices. ${ }^{29}$

Thus, it is not unlikely that Brazil may present the same abusive misuse of bleaching products, similarly to what is currently observed in the USA, in a phenomenon called "bleachorexics" or "whitening junkies". ${ }^{30}$ Since $35 \%$ of the medication used in Bra- 
zil is self-medication, ${ }^{25}$ information is of utmost importance, and dentists should be aware of the risks posed by the abusive use of OTC bleaching products. A possible reclassification of these products by the ANVISA should also be discussed.

\section{Conclusions}

Based on the present literature review, the following conclusions may be drawn:

1. Whitening toothpastes, whitening dental floss, and pro-whitening toothbrushes are superficial stain removing agents, and not bleaching agents perse.

2. Paint-on gels and rinses have lower levels of bleaching agents and may produce a whitening effect that does not seem to be clinically signifi-

\section{References}

1. Wash TF, Rawlinson A, Wildgoose D, Marlow I, Haywood J, Ward JM. Clinical evaluation of the stain removing ability of a whitening dentifrice and stain controlling system. J Dent. 2005;33(5):413-8.

2. Aschill TM, Hellwig E, Schmidale S, Sculean A, Arweiler NB. Efficacy, side-effects and patients' acceptance of different bleaching techniques (OTC, in-office, at-home). Oper Dent. 2005;30(2):156-63.

3. Hasson H, Ismail AI, Neiva G. Home-based chemically-induced whitening of teeth in adults (Review). Cochrane Database Syst Rev. 2006;4:1-43.

4. Meireles SS, Heckmann SS, Leida FL, Santos IS, Della Bona A, Demarco FF. Acceptability, efficacy and tolerability of $10 \%$ and $16 \%$ carbamide peroxide tooth-whitening gels: doubleblind randomized clinical trial. Oper Dent. 2008;33(6):60814.

5. American Dental Association (ADA). Acceptance Program Guidelines. Dentist dispensed home-use tooth bleaching products. April, 2006. Retrieved online November 7, 2008 from: http://www.ada.org/ada/seal/standards/guide_home_ bleach.pdf.

6. European Commission on Consumer Products. Scientific committee on consumer products. Preliminary opinion on hydrogen peroxide in tooth whitening products. Available from: http://ec.europa.eu/health/ph_risk/committees/04_ sccp/docs/sccp_cons_01_en.pdf SCCP. 2005;0844(4):1-50.

7. Donly KJ, Segura A, Henson T, Barker ML, Gerlach RW. Randomized controlled trial of professional at-home tooth whitening in teenagers. Gen Dent. 2007;55(7):669-74.

8. Food and Drug Administration (FDA). Center for Drug Evaluation and Research. Over-the-counter medicines: What's cant, as observed by the small number of clinical trials available.

3. Whitening strips seem to produce a whitening effect similar to that of $10 \% \mathrm{CP}$ in a tray, but the clinical studies reviewed were generally based on short-term evaluations and were performed with the manufacturers' financial aid.

4. Independent, long-term clinical trials should be performed to evaluate the effectiveness and side effects of OTC bleaching products.

5. Legislation varies largely among different countries, and clinicians should be acquainted with the available products and be aware of the potential abusive self-medication use of OTC products, which could produce harmful effects.

right for you? Washington March, 2006. Retrieved online November 7, 2008 from: http://www.fda.gov/cder/consumerinfo/WhatsRightForYou.htm.

9. Association Dentaire Française (ADF). Medical Devices Commission: Tooth Bleaching Treatments - A Review. 2007. Retrieved online November 7, 2008 from: http://www.adf.asso. fr/pdf/DossiersADF_EN/TOOTH-BLEACHING.pdf.

10. Lima DANL, Silva ALF, Aguiar FHB, Liporoni PCS, Munin E, Ambrosano GMB et al. In vitro assessment of the effectiveness of whitening dentifrices for the removal of extrinsic tooth stains. Braz Oral Res. 2008;22(2):106-11.

11. Joiner A, Philpotts CJ, Ashcroft AT, Laucello M, Salvaderi A. In vitro cleaning, abrasion and fluoride efficacy of a new silica based whitening toothpaste containing blue covarine. J Dent. 2008;36 Suppl 1:S32-7.

12. Gerlach RW, Barker ML, Tucker HL. Clinical response of three whitening products having different peroxide delivery: comparison of tray, paint-on gel, and dentifrice. J Clin Dent. 2004;15(4):112-7.

13. Sharma N, Galustians HJ, Qaqish J, Rustogi K, Zhang YP, Petrone ME et al. Comparative tooth whitening and extrinsic tooth stain prevention efficacy of a new dentifrice and a commercially available tooth whitening dentifrice: six-week clinical trial. J Clin Dent. 2004;15(2):52-7.

14. Joiner A, Philpotts CJ, Alonso C, Ashcroft AT, Sygrove NJ. A novel optical approach to achieving tooth whitening. J Dent. 2008;36 Suppl 1:s8-s14.

15. Gerlach RW, Barker ML. Randomized clinical trial comparing overnight use of two self-directed peroxide tooth whiteners. Am J Dent. 2003;16:17B-21B. 
16. Gerlach RW, Tucker HL, Anastasia MK, Barker ML. Clinical trial comparing 2 hydrogen peroxide tooth whitening systems: strips vs pre-rinse. Compend Contin Educ Dent. 2005;26(12):874-8.

17. Kugel G, Aboushala A, Sharma S, Ferreira S, Anderson C. Maintenance of whitening with a power toothbrush after bleaching treatment. Compend Contin Educ Dent. 2004;25(2):119-31.

18. Porciani PF, Grandini S, Perra C, Grandini R. Whitening effect by stain inhibition from a chewing gum with sodium hexametaphosphate in a controlled twelve-week single-blind trial. J Clin Dent. 2006;17(1):14-6.

19. Moore M, Hasler-Nguyen N, Saroea G. In vitro tooth whitening effect of two medicated chewing gums compared to a whitening gum and saliva. BMC Oral Health. 2008;8:23.

20. Kishta-Derani M, Neiva G, Yaman P, Dennison D. In vitro Evaluation of Tooth-color Change Using Four Paint-on Tooth Whiteners. Oper Dent. 2007;32(4):394-8.

21. Lo EC, Wong AH, McGrath C. A randomized controlled trial of home tooth-whitening products. Am J Dent. 2007;20(5):315-8.

22. Marson FC, Sensi LG, Vieira LCC, Araújo E. Clinical evaluation of in-office dental bleaching treatments with and without the use of light-activation sources. Oper Dent. 2008;33(1):1522 .

23. Gerlach RW, Barker ML. Professional vital bleaching using a thin and concentrated peroxide gel on whitening strips: an integrated clinical summary. J Contemp Dent Pract. 2004;5(1):1-14.
24. Nunes PF, Johnson BA, Breene RT. Selling to the moneyed masses. Harv Bus Rev. 2004;82(7-8):94-104,188.

25. Melo DO, Ribeiro E, Storpirtis S. A importância e a história dos estudos de utilização de medicamentos. Rev Bras Cienc Farmac. 2006;42(4):475-85.

26. Pereira FSVT, Bucaretchi F, Stephan C, Cordeiro R. Self-medication in children and adolescents. J Pediatr. 2007;83(5):4538.

27. Scientific Committee on Cosmetic Products and Non-Food Products Intended for Consumers (SCCNFP): Opinion on hydrogen (Carbamide, Zinc) peroxide in tooth bleaching/ whitening products. September, 2002. Retrieved online November 7, 2008 from: http://ec.europa.eu/food/fs/sc/sccp/ out180_en.pdf.

28. Food and Drug Administration (FDA). National Institutes of Health (NIH). Consumer Healthcare Products Association (CHPA). Adolescent over-the-counter (OTC) drug product use - Public Workshop. December, 2007. Retrieved online November 7, 2008 from: http://www.fda.gov/CDER/meeting/adolescent_OTC.htm.

29. Agência Nacional de Vigilância Sanitária (ANVISA). Resolução $\mathrm{RDC} \mathrm{n}^{\circ}$ 211. Julho 2005. Available from: http://e-legis.anvisa. gov.br/leisref/public/showAct.php?id=17882. Accessed 2008 Nov 7.

30. ABC NEWS. Primetime Health: "Bleachorexics" Risk Much For White Smile. February 3, 2005. Retrieved online November 7, 2008 from: http://abcnews.go.com/Health/Primetime/ Story ? id $=469468$ oppage $=1$. 